measured, for there is no place for Relativity in the measurement of heterophoria.

Of the means of measuring a deviation produced under the conditions laid down above, two are available. In the first, which involves the use of prisms, the false image is so transferred as to fall on the retinal meridian corresponding to that in the other eye on which the true image falls, and the patient thus sees what he would do if he were orthophoric. The second means requires the patient to read the deviation on a scale, and of this there are two varieties, depending on whether the scale is to be read by the eye which is seeing the fixation object, or by the other eye. In a test where, for example, an eye receives a distorted image, the other eye is required both to fix and to read a scale. Should a heterophoria exist, the part of the scale on which the distorted image falls cannot have its image received on the macula of the fixing eye, on which the image of the fixation-point already falls. The important section of the scale is therefore seen by a part of the retina with a lower visual acuity than the macula, and the direction of attention to this part of the scale immediately brings into play the fixation reflex, with the consequent vitiation of the measurement. To other tests, where the one eye fixes a single point, and the patient is asked where this point appears to be on the scale seen by the other eye, the same objection does not apply, for here the important part of the scale falls on the macula of the non-fixing eye. Practical experience, confirmed by statistical investigation, bears out this apparently theoretical criticism of the first variety.

To be concluded.

\title{
$\underline{ }$ \\ ANGIOMATOSIS RETINAE \\ With a report of four cases in one family \\ involving six eyes
}

BY

L. STAZ

JOHANNESBURG, SOUTH AFRICA

THE first clear description of this condition was given by Fuchs in 1882 .

D. J. Wood (1892), later of Cape Town, exhibited a coloured drawing of Mr. Tweedy's case to the Ophthalmological Society of the United Kingdom in 1891. The drawing is reproduced in Vol. XII of the Transactions of the Ophthalmological Society. It is of the right eye, and shows very peculiar enlargement of some of the 
blood vessels, and detachment of the retina on the outer side. In the left eye there was a complete detachment of the retina, and subsequently the eye was removed on account of the development of glaucoma in it. This is the eye which was examined microscopically by Treacher Collins (1894).

The right eye was subsequently removed elsewhere, but unfortunately no pathological report was obtained. Two years later this patient's elder sister came under the care of Mr. Morton at Moorfields, with both eyes blind, staphylomatous and painful. Both were excised.

A detailed microscopical examination was first reported by Treacher Collins (1894) under the title "Two cases, brother and sister with peculiar vascular new growth probably primarily retinal, affecting both eyes." He gave a characteristically detailed macroscopic and microscopic examination of the three eyes.

In Case 1, John M., aged 20 years, the fellow-eye of Dr. Wood's case, he found the effects of raised tension. There was an extensive detachment of the retina, with at one point a broad adhesion to the choroid.

Microscopically, the retinal vessels were enormously distended and it was difficult to distinguish arteries from veins. In that part of the retina which was adherent to the choroid he found a close plexus of small blood-vessels as in a capillary naevus.

In Case 2, Julia M., aged 26, both eyes had been blind since she was twelve years of age. On examination, both were enormously enlarged and acutely tender. In the right, there was a projection from the side about the size of a blackberry, occupying the outer canthus. On excision of the eyes there was much haemorrhage.

Macroscopic examination again showed the result of increased pressure from the intra-ocular tumours. In both eyes was found a layer of bone on the-inner surface of the choroid. In the right eye, there was a large prominent yellow-coloured mass, which was found microscopically to consist of numerous branching small capillary vessels, the walls of which were mostly one cell thick; amongst them were a few larger vessels with thicker walls. Between the blood vessels were cells with very large nuclei with a honey-combed protoplasm.

In the interior of the left eye was a partially decolourised blood clot, and in the anterior part was a large mass of greyish tissue with yellow patches and small spaces in it.

Microscopically, the cornea was found to be invaded by a new growth composed of a plexus of thin-walled capillary vessels, of precisely the same structure as that found in the right eye.

A similar vascular new growth was found internal to the bone on the inner surface of the choroid. No normal retinal tissue could be seen anywhere. 
Collins comments that there can be little doubt that the process which produced such extensive changes in Case 2 is commencing in Case 1. He states that in Case 1, the changes are evidently starting in the retina, the other changes being the ordinary ones associated with prolonged increased tension, and his opinion was that the condition is primarily retinal and in the nature of a capillary naevus, which in places has undergone cystic degeneration, and in its growth has invaded and caused absorption of surrounding structures such as the lens and iris and is beginning to encroach on the deeper layers of the cornea. Since Treacher Collins' elucidation of the pathology of the condition a number of cases have been recorded.

McDonald and Lippincott (1938) give studies on an enucleated eye, employing differential staining techniques.

Bedell (1931) published a paper in which three cases are reported in detail, and the progress is portrayed by means of fundus photographs. Cases previously reported in the literature are summarised and a bibliography of $3 \frac{1}{2}$ pages is appended.

A few points from this paper are :-

(1) Angiomatosis retinae has been reported less than 100 times. This, one thinks, must be an underestimate.

(2) The characteristic ocular lesions are located most frequently in the extreme fundus periphery and may, therefore, be overlooked.

(3) The vessel changes should attract one's attention.

(4) There are three distinctive types clinically :-

(a) With immense venous enlargement and fullness of the parallel artery. Exudate appears comparatively late.

(b) With whipcord artery and widened straight vein. Exudate is an early sign.

(c) With a swollen rounded elevated nerve head suggesting a choked disc.

(5) The disease has been recognised from early childhood to middle life, but perhaps it is most commonly found in the third decade.

Foster Moore (1912) reported a case of " bilateral angioma of the retina." The report is well illustrated, and attention should be paid to the blurring of the optic discs, the enormous dilatation of the arteries and veins, the anastomosis of branches of the arteries and veins in the substance and on the surface of the angioma, and also to what is referred to as-" an area of retinal degeneration on the temporal side of the disc."

The Doyne Memorial lecture delivered to the Oxford Opthalmological Congress by van der Hoeve (1932) should be consulted. The subject is the eye symptoms in the phakomatoses of Bourne- 
ville, von Recklinghausen and von Hippel-Lindau. In this lecture a family from Rochat's clinic is quoted in which retinal and intra-cranial tumours were associated. The entire lecture is of absorbing interest.

Cushing and Bailey (1928) published a paper on " haemangiomas of the cerebellum and retina." It is stated that angioma of the retina is usually known as Coats' disease or von Hippel's disease, but that in 1926 Lindau showed that the condition can be associated with (1) the presence of angioblastic cysts in the central nervous system, notably the cerebellum, (2) the presence of cysts in the kidney and pancreas, and (3) the development of hypernephromata and tumours of the suprarenal glands. In their case a cerebellar cyst was removed at operation and in the cyst wall a haemangioblastoma was found. This is a point which von Hemmes (circa 1930) stressed, viz.: if all cerebellar cysts were examined histologically it would be found that they are frequently a cystic dilatation of an haernangioma.

Cushing and Bailey note that an ophthalmologist who finds angiomatosis of the retina should realise the need of looking for cerebellar symptoms, since a cerebellar tumour of like sort most favourable for operation may be co-existent. The abstracter (F.A.W-N.) of their paper, remarks that it is gratifying to note that on looking through the literature they found that the true nature of the disease was first recognised by Treacher Collins in 1894.

It is essential to our conception of the disease that its neoplastic, though benign nature should be realised, since the secondary changes of reactive gliosis, iridocyclitis, separation of the retina and glaucoma serve ultimately to conceal the nature of the primary lesion as in cases of Coats' disease.

A case of " angiomata of the right retina with a normal left eye " is reported by Srinivasan (1934), and in the same Journal in a report on the Annual Congress, 1933, of the All-India Ophthalmological Society is the following statement: "The Madras School of Ophthalmology produced an interesting paper by Lieutenant-Col. Wright and his staff on " von-Hippel-Lindau's disease." Only the three cases had been seen out of more than a quarter of a million fundus cases examined in Madras.

Niccol and Foster Moore (1934) reported a case of " angioma of the retina" involving the optic disc with a pathological report by Stallard.

Kuhn (1931) reported an interesting case of " angioma of the nerve head." A male, aged 54 years, attended for removal of a corneal foreign body and ophthalmological examination revealed an old venous thrombosis in the right fundus. The temporal border of the right disc was partially covered with a fibrous exudate and 
there was endarteritis of the retinal vessels. In the left eye glaucoma simplex was diagnosed. Five months later, on examination by Wiener, the vessels on the temporal quadrant of the right disc were very tortuous and kinked with marked variations in their calibre. There was a glomerulus-like protusion from the nasal half of the disc fully 2 dioptres forward. Its colour was a dirty chocolate grey. The veins in general were about twice the size of the accompanying arteries and very engorged. There was no haemorrhage or exudate. In the left eye the optic disc was cupped. Wiener expressed an opinion that a neoplasm was growing from the right nerve head, and that it was probably an angioma. Kuhn suggests that an angioma might complicate the recovery from venous thrombosis of the retinal vessels and queries - " can it lead to malignancy?"

Krug and Samuel (1932) reported a case of venous angioma of the retina, optic nerve, chiasm and brain with post-mortem observations.

The four cases which are the subject of this report consist of the family G., who were first examined at the General Hospital, Johannesburg, in 1932. Mrs. G. and her daughter Gertie attended the Out-patient Department on February 9, 1932, under Dr. R. C. J. Meyer, to whom I am indebted for permission to publish these cases.

(1) The mother, Mrs. Helena G., a widow aged 43 years.

(2) Her daughter, Gertie G., aged 19 years.

(3) One son, Theodore G., aged 18 years.

(4) An elder son Jacob G., aged 22 years.

\section{Examination}

(1) Mrs. G., aged 43, stated that her left eye had been blind since 1910. . Blindness .occurred for one week, but vision was restored by glasses, for an unknown period. From 1910 to 1920 she was under the care of an ophthalmic surgeon, who treated her with tablets and drops. She stated that a "blood examination" taken during that time was negative. She came up to the Hospital now because she was afraid her right eye was going the same way.

The left eye was found to be blind, with no perception of light. There was an iris bombé, and numerous blood-vessels were visible over the iris and lens remains, which was calcareous. The eye was not painful. 
In the right eye vision $=4 / 18$, not improved by glasses. The fundus showed gross changes. (Fig. 1.) There was massive exudate of the retina (Coats' disease). The veins were enormously distended and "down and in " one disappared into an angioma, while another branch crossed the angioma which lay in a grey area of retina. The massive exudate was crossed by retinal vessels, and there were some highly refractile spots of cholesterin crystals. Some vessels had a beaded appearance and beyond the angioma

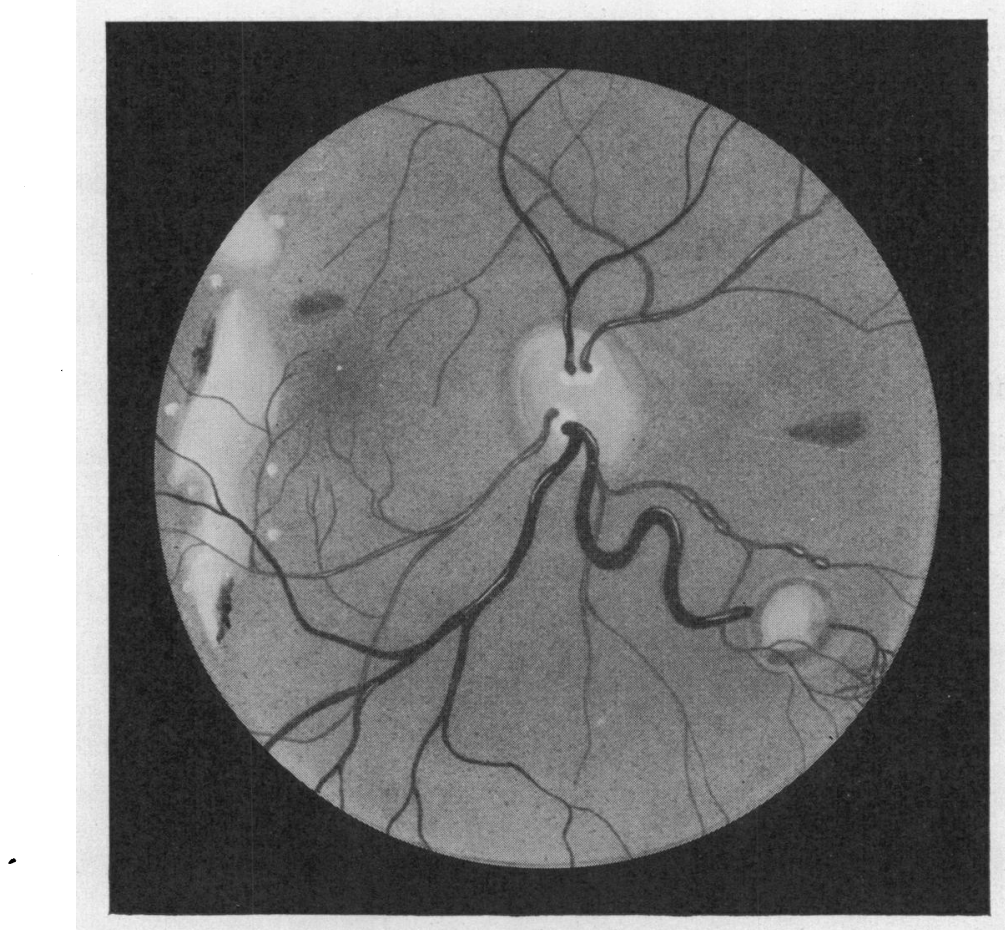

FIG. 1.

was an area of dilated capillaries. Above the macular region was a retinal haemorrhage and also one near the angioma. The optic disc was slightly blurred.

The patient's family history revealed nothing of interest excepting that she was one of nine children, most of whom were dead. Her twin sister died at the age of four months of " convulsions." She was not related, before marriage, to her husband, he being a Russian and she an Afrikander.

(2) The daughter Gertie G., aged 19 years, was also seen on February 9, 1932. She had an almost blind divergent right eye. 
She complained of headaches, but no vomiting. She stated that her right eye had suddenly gone blind about nine months previously-before that she had seen a "black spot" for about a year.

On examination of the right eye (Fig. 2), a large detachment of the retina below and on the temporal side was found. On the surface of the detachment were two areas of capillary naevi, and many

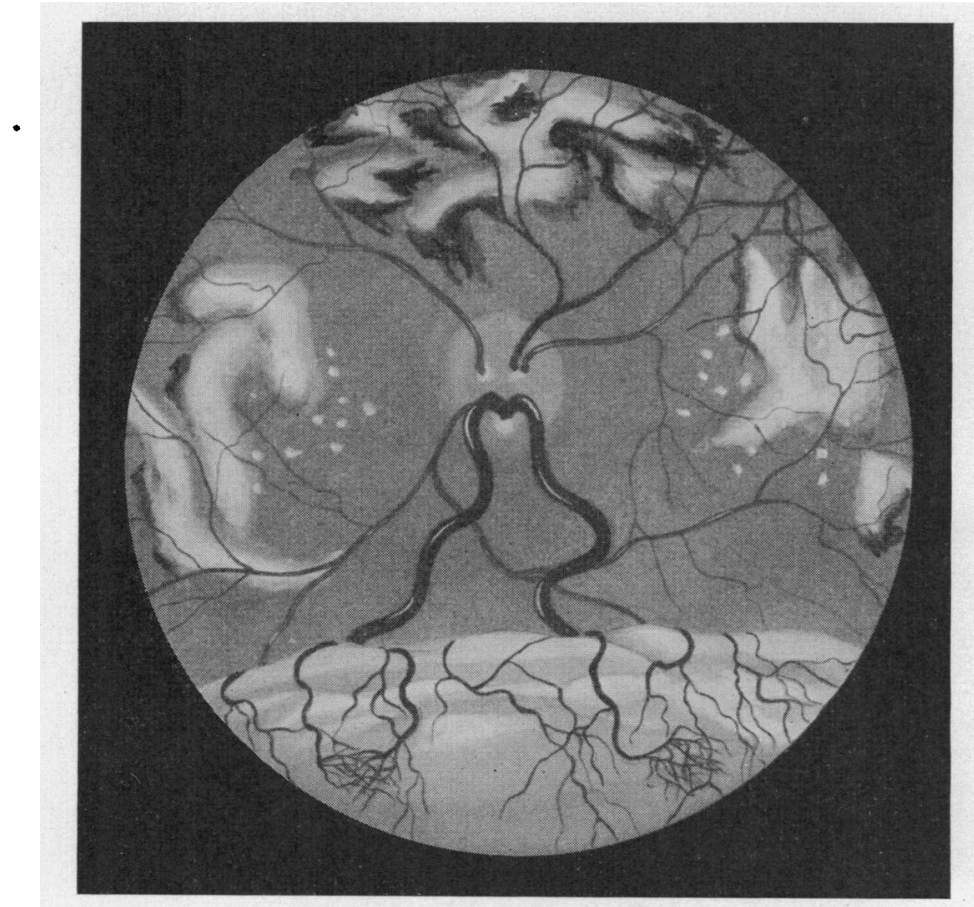

FIG. 2.

newly-formed blood vessels. There was widely scattered chorioretinitis, especially above, and large areas of massive exudate in the retina with highly refractile crystals scattered about. There was also retinitis proliferans with vessels growing forward into the vitreous. The optic disc was very blurred. The anterior chamber was of good depth, and the tension normal.

In the examination of the left eye, on that date, vision was $4 / 4$ and J.1, emmetropic. There was one glistening spot above the macula, otherwise quite normal.

On finding the condition of angioma of the retina in mother 
and daughter, a request was made that the remaining members of the family should be sent up for examination. This consisted of two boys.

(3) On Feb. 16, 1932, Theodore G., aged 18 years, was examined. His vision was-Right $=6 / 5$, Left $=6 / 6$. With the pupils fully dilated, in the right eye (Fig. 3) was found a pink pear-shaped angioma in the extreme periphery at 8 o'clock, lying in a grey

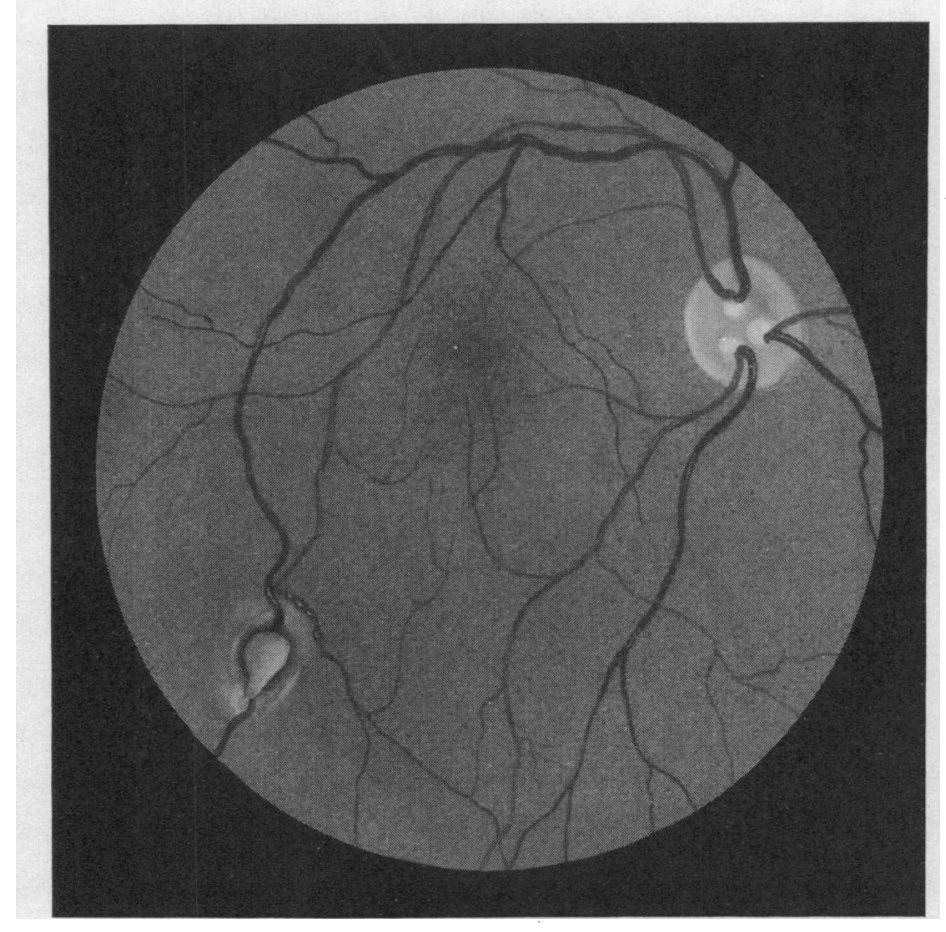

FIG. 3.

area. An artery and vein are in contact, but do not anastomose, just before the vein disappears into the tumour. In the left eye no angioma was found, and this was confirmed at subsequent examinations.

(4) On April 27, 1933, the last member of the family reported for examination-Jacob G., aged 22 years, a brother of Gertie and Theodore $G$. His vision was-Right $=6 / 4$, Left $=6 / 5$. In his right eye nothing abnormal was detected, but in his left eye on looking downwards, an angioma was found at 6 o'clock (Fig. 4). The vessels were not engorged but a branch of artery and a vein dis appeared into the tumour from opposite sides. The colour of the 




FIG. 4.

tumour, unfortunately, was not noted. In the lower nasal quadrant of the retina was an elongated patch of exudate.

This patient has not reported for further examination.

\section{Progress Notes}

Case 1. Mrs. Helena $G$. This patient did not appear again until May, 193\%, by which time her right eye was almost completely blind as a result of massive exudate in the retina and widespread detachment of the retina. The pupil still reacted to light, and vision $=$ perception of light vaguely.

She was treated by suture of radium needles to the sclera, as will be described later.

Case 2. Gertie G. This girl was lost sight of until she appeared again at my rooms on April 25, 1933, aged 21 years. On that occasion the detachment of the retina in the right eye was found to be progressing but in the left eye now, " up and out," was a small round whitish area into which an artery and vein disappeared. Crossing its surface could be seen very fine vessels. The size of this spot which I took to be an early angioma was 
approximately $1 / 5$ of the diameter of the optic disc. (cf. Stallard (1933) Fig. 57, p. 65.) No mention of this new development was made to the patient, but she was requested to report at intervals, which she has done.

On September 29, 193.3, the condition in the right eye was found much advanced. There was an almost total detachment of the retina with more fibrous bands in the vitreous, and at deeper level

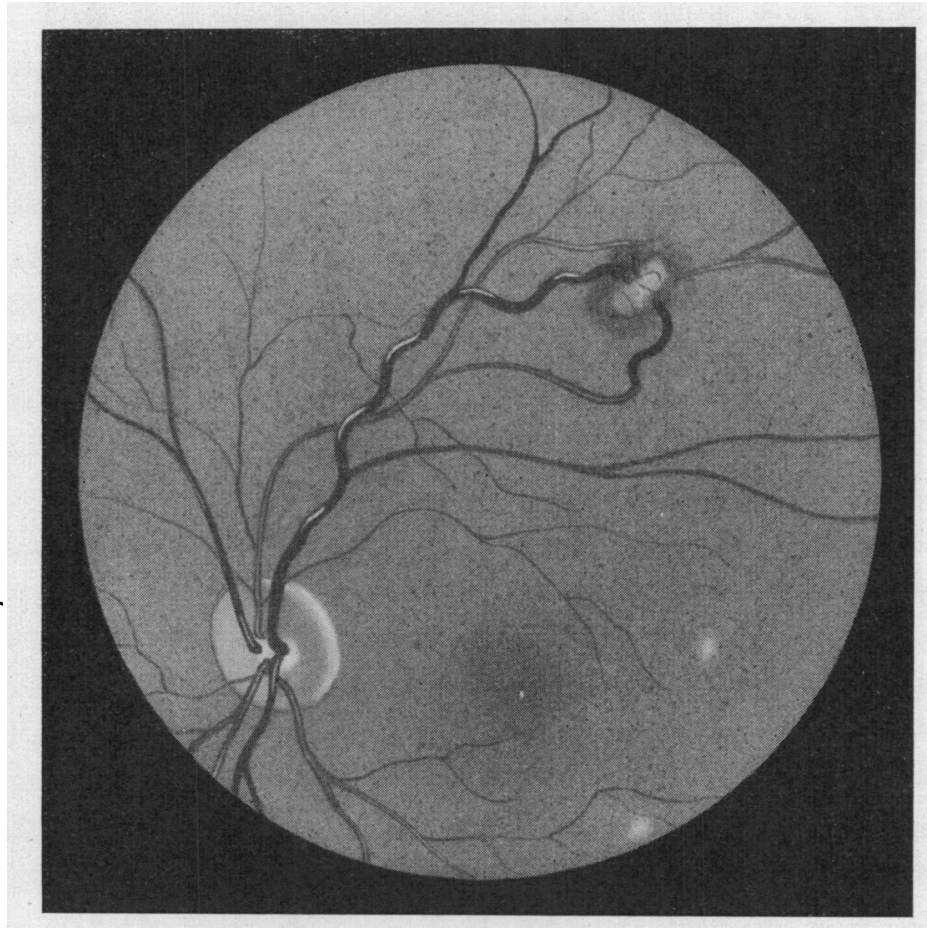

Fig. 5.

muddy looking retina could be seen. The anterior chamber was practically obliterated and the tension +2 , but she did not complain of pain. By this time Foster Moore's (1931) report of cases of glioma of the retina treated by radon, had been published, and one wondered whether the same technique could be applied to angiomata in spite of the fact that they are not " new growths." Not having the facilities however, she was referred to the X-ray Dept. of the General Hospital where she received deep X-ray therapy. This course was not completed as she had a very bad local reaction, and would not return for further treatment. After this treatment tension in the eye became lower, but not normal. In the meantime, the angioma in the left eye became larger, and its area was about one third that of the optic disc. 
The patient did not report again until August 24, 1934, when the following condition was found :-

Right Eye.-There was still some erythema of the skin on the right side of the face, as the result, she alleged, of the X-ray reaction and the palpebral orifice was narrowed. Tension was normal and the anterior chamber less shallow. The pupil was not circular, but was adherent in places to the lens which was totally opaque. These sequelae, I think, were mainly due to the X-ray therapy which, however, had the desired effect of relieving, for the time being at any rate, the increasing tension in the eye.

Left Eye (Fig. 5).-The condition in the left eye showed some advance in the size of the angioma, which now had a pigmented edge. There was no undue fullness in the retinal vessels. At four o'clock was a small area which looked suspiciously like early exudate.

October, 1938, and February, 1939.-Apart from a very gradual increase in the size of the angioma in the left eye, there have been no further developments, and treatment as will be described later, has been advised.

Case 3. Theodore G., August 24, 1934.-Right Eye.-The affected vein was slightly engorged, and on reaching the angioma it seemed to spread out into the tumour. The angioma still lay embedded in a grey area of retina and did not appear to have grown appreciably. It was found that the anastomosis between artery and vein above the tumour was only apparent. The artery appeared to touch, but not actually anastomose with the vein. Beyond this point the artery showed beading.

His general health was good, excepting for chronic appendicitis, for which he was shortly being admitted to hospital for appendicectomy.

October, 1938, and February, 1939.-There has been no appreciable change in the eye excepting some enlargement of the angioma. The fundus picture in this case is particularly beautiful. The angioma has the appearance of a small pink pear embedded snugly in the retina. The retina is greyish and raised as though to grasp the angioma firmly.

Case 4. Jacob G.-Owing to a family quarrel this patient has entirely disappeared, and no further examination of his eyes has been possible.

None of these patients has any sign of disease of the central nervous or other systems as yet.

\section{Treatment}

From a study of the work of Foster Moore $(1931,1933)$ and H. B. Stallard (1933), it appeared that these cases should be treated by the suture of radon seeds to the sclera over the site of the tumour. 
Traquair (1932) treated one case with radium. As radon seeds are not available in Johannesburg, Case 1, Mrs. H. G., received the following treatment by means of radium needles sutured to the exposed sclera in the region of the angioma in the right eye :-

June 3, 1937. $\quad 1 \times 10 \mathrm{mgm}$. filtered short needles for 2 hours. July $24,1937.3 \times 10 \mathrm{mgm}$. , , , , , , 3 hours. Jan. 21, 1938. $10 \times 1 \mathrm{mgm}$. ", , , , , 95 hours.

There was no improvement in the appearance of the fundus, and in a personal discussion in 1938, Stallard pointed out that after the use of radon and radium there is a danger of delayed macular degeneration.

Weve (1937) reported " The surgical treatment of intra-ocular tumours with retention of the eye-ball." A case of angioma of the retina with detachment of the retina was treated by him with definite improvement.

It is felt that the method of choice in the treatment of these cases is surface coagulation by means of the diathermy, after " transillumination localisation" of the angioma according to the technique of Weve.

Such treatment was offered to Case 2 and Case 3 , but the patients received charitable assistance which enabled them to proceed to London for treatment. No doubt their further history will be reported from there at a later date.

The accompanying fundus paintings have been done from diagrams, as no artist is available to paint directly from the living patient. Figs. 1 and 2 are composite.

\section{Summary}

(1) A brief résumé is given of the original histological examinations of angioma of the retina.

(2) Some reports of recent cases and publications on the subject are referred to and abstracted.

(3) Angiomatosis retinae in a family consisting of a mother and three children, involving six eyes is reported.

(4) Unsuccessful treatment in one very advanced case, by means of radium needles is reported, and treatment by diathermy surface coagulation according to the technique of Weve is suggested.

\section{BIBLIOGRAPHY}

1. BEDELL .-Amer. Jl. of Ophthal., p. 389, May, 1931.

2. Treacher Collins. - Trans. Ophthal. Soc. U.K., Vol. XIV, p. 141, 1894.

3. Cushing and BaILEY.-Arch. of Ophthal., September, 1928. Abstract in Brit.Jl. Ophthal., p. 44, 1931. 
4. Foster Moore.-Trans. Ophthal. Soc. U.K., Vol. XXXII, p. 76, 1912.

5. - Brit.Jl. of Ophthal., p. 673, 1931.

6. - Proc. Roy. Soc. Med., March 10, 1933.

7. Trans. Ophthal. Soc. U.K., Vol. LIII, 1933.

8. KRUG and SAMUEL. - A rch. of Ophthal., pp. 871-879, December, 1932.

9. KuнN.-Amer.Jl. Ophthal., p. 427, 1931.

10. MCDONALD and LipPINCOTT.-Arch. of Ophthal., Vol. XX, No. 6, p. 958, December, 1938.

11. NicCOL and MOORE.-Brit. Jl. of Ophthal., p. 434, August, 1934.

12. SRINivaSAN.-Brit. Jl. of Ophthal., 1934.

13. Stallard.-Brit. Jl. of Ophthal. Monograph VI. Radiant Energy in Ophthalmic disorders, 1933.

14. Traquair.-Trans. Ophthal. Soc. U.K., Vol. LII, p. 311, 1932.

15 VAN DER Hoeve.-Trans. Ophthal. Soc. U.K., Vol. LII, p. 380, 1932.

16. VON HEMMES.-Groeningen. 1930.

17. WeVe, H. J. M.-Arch.f. Augenheilk., Vol. CX. Bd., 1937.

18. Wood, D. J.-Trans. Ophthal. Soc. U.K., Vol. XII, 1892.

\section{ANNOTATION}

\section{Eye Injuries in Air Raids}

Ophthalmology has been called the Cinderella of Medicine and Surgery, left alone to fend for herself, often with meagre accommodation and equipment, in a general hospital. On December 29, the night of the severest incendiary raid on London to date, Cinderella was much in evidence with the cinders and was very much occupied long after midnight. At one large eye hospital in the City, 280 corneal and conjunctival foreign bodies were removed from members of the Fire Services between midnight and $5.30 \mathrm{a} . \mathrm{m}$. Charred material formed the bulk of these foreign bodies. Most of the men had been attended to at First Aid Posts by the instillation of castor oil drops, had returned to their duties, been compelled to retire again on account of discomfort and then visited an eye surgeon. The first 100 to be treated all removed their pad and bandage on leaving the hospital to return to their duties of firefighting and so for the remainder this therapeutic refinement was dispensed with, thus affording a saving of time and material. The eye injuries caused by flying glass have been severe and on one night at a general hospital in the City the eye surgeon operated from 8 p.m. to 5.30 a.m. There were three cases in which both eyes were penetrated by splinters of glass, the most tragic being a husband and wife. Eyes containing glass fragments shrink relatively quickly, save in a few exceptional cases where a glass fragment has been retained in the vitreous for years without complications.

It is difficult enough to persuade industrial workers to adopt devices for their ocular protection and likewise it seems that firemen 